\title{
THE ASSOCIATION BETWEEN \\ PARENTAL RELIGIOSITY, STRESSFUL LIFE EVENTS, AND PROBLEM BEHAVIOR IN PRE-ADOLESCENTS AND ADOLESCENTS ${ }^{* *}$
}

\author{
(Received: 6 March 2019; accepted: 31 October 2019)
}

Objective: To investigate whether religiosity influences exposure to stressful life events (SLEs) and whether religiosity moderates the effects of SLEs, resulting in fewer problem behaviors.

Method: The self-reported mental health problems of a community-based longitudinal sample of pre-adolescents $(n=2230)$ in the three northern provinces of the Netherlands were assessed in early adolescence (12-15 years, Youth Self-Report, YSR) and in adolescence (18-21 years, Adult Self Report ASR). The sum scores for SLEs in early adolescence were based on the previous two years. The variable parental religiosity was based on information obtained in pre-adolescence (10 12 years). Associations between religiosity and SLEs and whether parental religiosity is a moderator between SLEs and problem behaviors were studied, using repeated measures ANOVAs.

Results: Having actively religious parents was associated with fewer SLEs. Parental religiosity did not moderate the association between SLEs and problem behavior.

\footnotetext{
Willeke van der Jagt-Jelsma, GGZ Drenthe, Dr. G.H. Amshoffweg 3, 7909 AA Hoogeveen, The Netherlands; willeke.van.der.jagt@ggzdrenthe.nl.

** This research is part of the TRacking Adolescents' Individual Lives Survey (TRAILS). Participating centers of TRAILS include the University Medical Center and University of Groningen, the University of Utrecht, the Radboud Medical Center Nijmegen, and the Parnassia Bavo group, all in the Netherlands. TRAILS has been financially supported by various grants from the Netherlands Organization for Scientific Research NWO (Medical Research Council program grant GB-MW 940-38-011; ZonMW Brainpower grant 100-001-004; ZonMw Risk Behavior and Dependence grants 60-60600-97-118; ZonMw Culture and Health grant 261-98710; Social Sciences Council medium-sized investment grants GB-MaGW 480-01-006 and GB-MaGW 48007-001; Social Sciences Council project grants GB-MaGW 452-04-314 and GB-MaGW 452-06-004; NWO large-sized investment grant 175.010.2003.005; NWO Longitudinal Survey and Panel Funding 481-08-013 and 481-11-001), the Dutch Ministry of Justice (WODC), the European Science Foundation (EuroSTRESS project FP-006), Biobanking and Biomolecular Resources Research Infrastructure BBMRI-NL (CP 32), and the participating universities. We are grateful to everyone who participated in this research or worked on this project to make it possible.
} 
Conclusions: The children of actively religious parents experienced fewer SLEs in pre-adolescence than did the children of non-religious parents or the children of parents with incompatible religious beliefs, but parental religiosity did not moderate the effects of SLEs on problem behaviors. Reasons for the absence of a religious coping effect are discussed. ${ }^{1}$

Keywords: internalizing problem behavior, externalizing problem behavior, problem behavior, pre-adolescents, adolescents, religion, religiosity, stressful life events

\section{Introduction}

Like other world views, holding religious beliefs (religiosity) provides individuals with values, a way of life, and ethically appropriate behavior (JOSEPHSON \& MABE 2004; Moreira-Almeida et al. 2006; GeORGE et al. 2002; LAUFER et al. 2010). Most studies, (KoENIG et al. 2001; KoENIG et al. 2012; VAN DER JAGT-JELSMA et al. 2011; VAN DER JAGT-JELSMA et al. 2015; VAN DER JAGT-JELSMA et al. 2018) but not all (BONELLI \& KOENIG 2013; VAN DER JAGT-JELSMA et al. 2017), have shown religiosity to be beneficial to mental health. Religiosity may be beneficial to mental health by influencing the degree of exposure to stressful life events (SLEs) as a result of a less externalizing lifestyle and providing a way of dealing with SLEs (JOSEPHSON \& MABE 2004; Moreira-ALMEIDA et al. 2006; GEORGE et al. 2002; LAUFER et al. 2010; KoENIG et al. 2001; KoENIG et al. 2012). This 'religious' dealing with SLEs is known as religious coping (PARK 2005; PARGAMENT 1997; PARGAMENT et al. 2011), which is particularly relevant to those individuals for whom their faith is an integral part of their lives (PIEPER et al. 2012).

We investigated the association between parental religiosity, SLEs, and problem behavior. Below we discuss the relationship between SLEs, problem behavior and parental religiosity, then elaborate on how religiosity relates to mental health and how religiosity may moderate the relationship between SLEs and problem behavior.

\subsubsection{The relationship between mental health and SLEs}

Although there are differences in how SLEs are conceptualized (GRANT et al. 2003), it is generally recognized that SLEs have a negative effect on internalizing and externalizing problem behaviors in pre-adolescence (SERAFINI et al. 2015; KING \& ROESER 2009). Moreover, the association between SLEs, internalizing, and externalizing problem behaviors is influenced by a number of factors, such as the child's characteristics, environmental factors, biological, psychological, and social processes (KING $\&$ ROESER 2009). The TRAILS study was designed to chart and explain the development of, and risk factors for, mental health problems since children will gradually develop into adults. Some of the TRAILS studies have investigated the association

\footnotetext{
1 Abbreviations: TRAILS = TRAcking Adolescents' Individual Lives Survey, YSR = Youth Self-Report, ASR $=$
} Adult Self Report, Stressful Life Events = SLEs. NOTE: the terms 'religion' and 'religiosity' are used interchangeably 
between SLEs, internalizing, and externalizing problem behaviors (BoumA et al. 2008; BAKKER et al. 2010). For example, BOUMA and colleagues (2008) investigated whether parental depression and gender affected the association between SLEs and the probability of depressive problems in early adolescence. They measured SLEs as the sum score of responses to a questionnaire describing 36 possible events. Results showed that parental depression versus no depression was associated with a higher sensitivity of adolescents to the depressogenic effect of SLEs. Furthermore, girls were more sensitive to these effects than boys. BAKKER and colleagues (2010) found that boys and girls were sensitive to different types of peer stressors, and that peer stress was associated with different mental health problems in boys and girls. In sum, SLEs have negative effects on internalizing and externalizing problem behaviors, with gender indirectly playing a role in this association (SERAFINI et al. 2013; KING \& ROESER 2009; BOUMA et al. 2008; BAKKeR et al. 2010).

\subsubsection{The relationship between religiosity and SLEs}

It is argued that religiosity may be beneficial to mental health by reducing exposure to SLEs, thus reducing problem behavior as a consequence. This may be because religiosity is related to health-promoting behavior (such as abstinence from alcohol, tobacco, regulations concerning sexual practices, following rules in traffic) (KoENIG et al. 2001; KoENIG et al. 2012), and to a more cautious and less impulsive lifestyle. These extend to the social environment of pre-adolescents and adolescents, families, and friends (KoENIG et al. 2012). A religious value-oriented lifestyle in a family is more likely if both parents are actively religious than if parents have different religious beliefs or no religious beliefs. Seemingly, the children of two actively religious parents probably live in a more protective environment, leading to a decreased risk of exposure to certain SLEs.

\subsubsection{The relationship between religiosity and mental health}

Most studies (72\%) from the past 30 years (mainly from North America) found religious involvement to be modestly associated with better mental health and fewer mental disorders and with better physical health and longer survival (LARSON 1992; BONELLI \& KOENIG 2013; COTTON et al. 2006), with a mean correlation of 0.10 across all conditions (HACKNEY \& SANDERS 2003). As religiosity is a multidimensional construct (KoENIG et al. 2001; KoENIG et al. 2012; VAN DER JAGT-JELSMA 2018), the measurement of the relationship between religiosity and mental health is complicated. As a consequence, different measures show different relationships with religiosity. Also, there are numerous potential confounding factors.

In an earlier study, religious disharmony between parents was found to be a risk factor for internalizing problems when the mother was passively religious (having answered being 'a religious person', possible affiliation to a church or denomination, but no active religious involvement). Religious disharmony was a risk factor on its 
own for externalizing problems amongst boys. However, the significance of findings was quite weak, and a longitudinal study involving the same population did not report statistically significant findings (VAN DER JAGT-JELSMA et al. 2015).

In understanding the relationship between religiosity and mental health, two examples of well-known models are described regarding the question how religiosity may impact mental health, regardless of the presence or absence of stress factors (VAN DER JAGT-JELSMA 2018). Both models depart from a cognitive-behavioral perspective, namely, a model based on the appraisal of life events, and a model concerning selfregulation of thought processes and behavior. Concerning the first model, religious coping enables a person to appraise life events and gives meaning to life, increasing a person's acceptance of events, which in turn provides comfort and hope in times of adversity (KoENIG et al. 2001; Koenig et al. 2012; PARK 2005; VAN DER JAGT-JelSMA 2018; PIEPER \& VAN UDEN 2005). The second model points towards the fact that many religions foster a spirit of self-regulation, by prescribing behaviors that have a positive influence on health, such as being moderate in eating and drinking, in smoking and drug use, being monogamous, or adhering to rules and regulations (MOREIRA-ALMEIDA et al. 2006; KoEnig et al. 2001; Koenig et al. 2012; Bonelli \& KoENIG 2013; CotTon et al. 2006). The benefits of public and private religious practices entail positive emotions, such as peace and less negative emotions, for example, a lower level of anxiety and frustration (VAN DER JAGT-JELSMA 2018). In this sense, religious practices can be seen as a way to achieve greater self-regulation. Public and private religious practices bring a feeling of peace and lower anxiety and frustration levels and can also be seen as a way to achieve greater self-regulation (VAN DER JAGT-JELSMA 2018).

\subsubsection{Mechanisms by which religiosity moderates the relationship between SLEs and mental health}

The next question is how religiosity reduces the impact of life stress (i.e. SLEs) on internalizing and externalizing problem behavior (VAN DER JAGT-JELSMA 2018; PIEPER $\&$ VAN UDEN 2005). In addition to the above-described cognitive-behavioral effects of religiosity, religious people often have extended social networks and feel supported by their group or church community (MOREIRA-ALMEIDA et al. 2006; VAN DER JAGT-JELSMA 2018). Active involvement in a religious community increases the chance of making social contacts that may develop into supportive friendships. This results in the emotional support needed to cope with life events and can prevent internalizing and externalizing problems (Koenig et al. 2001; van DeR JAGT-Jelsma 2018; MYers 1996).

While most studies have focused on SLEs caused by nature, such as natural disasters, and on SLEs caused by humans, such war and terrorism (KoENIG et al. 2012), few studies involving (pre-) adolescents have investigated whether religiosity diminishes the negative effects of SLEs on internalizing (LAUFER et al. 2010; LACEULLE et al. 2015) and externalizing problems (KABIRU et al. 2014; JOHNSON \& MORRIS 2008; PALAMAR et al. 2014). One study involving 8- to 12-year-olds assessed the association between SLEs and post-traumatic growth over time (LACEULLE et al. 2015). Spiritual 
growth was greater in religious children than in non-religious children, showing religiosity to have a protective function (LACEULLE et al. 2015). Another study, among Israeli youths (aged 13-15 years) exposed to terror, examined the role of religiosity and political ideology in the association between terror and posttraumatic growth (LAUFER et al. 2010). Both religiosity and political ideology mediated the effects of exposure and fear on growth, suggesting that cultural worldviews, such as religiosity and political ideology, may assist in the process of coping with a traumatic event and managing fear (LAUFER et al. 2010).

Most cross-sectional studies have reported that religiosity moderates the relationship between SLEs and externalizing problems; for example, the association between SLEs and delinquency was attenuated by high levels of religiosity (KABIRU et al. 2014; JOHNSON \& MORRIS 2008). In a cross-sectional African study of 3064 adolescents (aged 12-19 years) living in an urban area in Africa, an area known for extreme adversity (KABIRU et al. 2014), SLEs were positively associated with delinquency. Parental monitoring, religiosity (measured as a composite measure from five items), and selfesteem moderated the effect of adversity on delinquent behavior. A cross-sectional US study involving young adolescents (mean age 12.4 years) examined whether religiosity moderated the association between SLEs and problem behavior (JOHNSON \& MORRIS 2008). This study measured religiosity with questions about intrinsic religiosity and salience of religion. SLEs were measured as the sum score of a 20 -item questionnaire. The frequency of alcohol, tobacco, and/or marijuana use was used as a measure of externalizing problem behavior. Religiosity was found to moderate the association between SLEs and the frequency of alcohol, tobacco, and/or marijuana use. However, a study of US adolescents did not find religiosity to moderate the association between SLEs and delinquency (JOHNSON \& MORRIS 2008). Lastly, another US study found the protective effect of religiosity in the association between SLEs and drug and alcohol use to be dependent on the level of exposure to drugs and alcohol, as high exposure diminished the protective effect of religiosity (PALAMAR et al. 2014).

In summary, religiosity in growing pre-adolescents and adolescents has been shown in most, but not all, studies to moderate the association between SLEs, anxiety, posttraumatic growth, also between SLEs and externalizing problem behavior in particular. On the basis of the above studies, we hypothesized (i) that children growing up in a strongly religious environment will experience fewer SLE than the children growing up in a less religious or non-religious environment, and (ii) that these children will show less of a problem behavior over time after they have experienced SLEs than children growing up in a less religious or non-religious environment.

\section{Methods}

\subsection{Study design}

The Tracking Adolescents' Individual Lives Survey (TRAILS) is a prospective cohort study of Dutch pre-adolescents (age 10-12 years old) with four waves of assessment. 
The key objective of TRAILS is to chart and explain the development of mental health problems from pre-adolescence into adolescence (17-21 years), in terms of both psychopathology, and the underlying vulnerability and environmental risks. As the incidence of emotional and behavioral problems increases substantially in adolescence, pre-adolescents were monitored every two years until 24 years of age. This report used data collected during the first, second, and fourth waves of assessment, when the participants were aged $10-12$ years, $12-15$ years, and 18-21 years, respectively.

The mental health problems of a community-based longitudinal sample $(\mathrm{n}=$ 2230) of pre-adolescents were assessed using self-report in early adolescence (12-15 years, Youth Self-Report, YSR) and in adolescence (-21 years, Adult Self Report ASR). In early adolescence, the sum scores for SLEs were based on the previous two years. The variable 'parental religiosity' was based on information obtained from the parents when their children were 10-12 years old.

The survey was approved by the national ethics committee 'Centrale Commissie Mensgebonden Onderzoek'. Informed consent was obtained from all parents after the nature of the study had been fully explained to them. Children were excluded from the study if they were incapable of participating because of mental retardation or a serious physical illness or handicap; if no Dutch-speaking parent or parent surrogate was available; and if it was not feasible to administer part of the assessment in the parent's language. Of all children approached for enrolment in the study (i.e. selected by the municipalities and attending a school that was willing to participate, $\mathrm{n}=3145$ ), $6.7 \%$ were excluded because of incapability or language problems. A detailed description of the sampling procedure and method is provided elsewhere (AMONEP'OlAK et al. 2009).

\subsubsection{Pre-adolescent and adolescent mental health}

In early adolescence, the Youth Self-Report (YSR) questionnaire from 'the Achenbach System of Empirically Based Assessment (ASEBA) was used (ACHENBACH 1991). This questionnaire contains 112 items about behavioral and emotional problems, scored 0 (not true), 1 (somewhat or sometimes true), or 2 (very true or often true). The ratings were based on the past six months. We used the sum scores for internalizing and externalizing problem behaviors of the YSR. In adolescence, we used the Adult Self Report (ASR), also from ASEBA (ACHENBACH \& RESCORLA 2003). This questionnaire contains 102 items about behavioral and emotional problems, scored in the same way as in the YSR and also based on the past six months. We also used the sum scores for internalizing and externalizing problem behaviors of the ASR.

\subsubsection{Religion}

Parental religiosity was assessed using three descriptive questions regarding religion - Are you a religious person? Are you affiliated to a church or denomination? and 
How frequently do you attend church? Mothers usually answered for their partners. Answers were dichotomized into 'yes'/'no' answers, with parents being assigned to the category 'no religiosity' (no 'yes' answers), 'passive religiosity' (first or first and second question answered with 'yes', third question answered with '(almost) never'), and 'active religiosity' (first and second question answered with 'yes', third question answered with 'monthly' or more). Only if none of the questions were answered were the variables 'religiosity mother' or 'religiosity father' considered missing. These categories were chosen because they are related to increased religiousness, going from non-religious harmony (both parents are non-religious), religious disharmony (one parent religious and one non-religious), religious dysbalance (both parents religious, but one parent passively religious and the other actively religious), passive religious harmony (both parents are religious and/or are affiliated with a church or denomination), to active religious harmony (two parents go to church monthly or more often).

\subsubsection{Stressful life events}

SLEs included chronic stressors and were assessed in early adolescence with a questionnaire developed specially for the TRAILS study and for this age group. The SLEs had occurred in the two years before the assessment. We selected 22 clearly negative stressful life events from the 52 possible negative and positive events included in the questionnaire. Several TRAILS studies have made use of this questionnaire, using either 25 items (BOUMA et al. 2008), 20 items (BAKKER et al. 2010) or 22 items (AMONE-P'OlaK et al. 2009), depending on the research questions. The Cronbach's alpha was 0.56 , which is satisfactory. To study the relationship between SLEs, religiosity, and problem behavior, we chose those SLEs that would directly affect the participants, such as parental death or divorce, severe illnesses in the family, romantic relationship break-ups, etc. Table 2 shows the 22 items, together with the number of participants and the percentage of the study population that reported experiencing the SLE. As this variable was highly skewed, data were log transformed.

\subsubsection{Data analysis}

The frequency and percent distribution of the categorical variables are reported, as well as means and standard deviations $( \pm S D)$ for continuous variables. Scores for internalizing and externalizing problem behaviors are reported as mean scores. Sum scores of SLEs were calculated and $\log$ transformed. Analyses were performed with the statistical package IBM SPSS Statistics 24.

The first hypothesis was analyzed with an ANOVA analysis, with SLEs as a dependent variable and parental religiosity as an independent variable. For the second hypothesis, two preliminary regression analyses were carried out to investigate the association between SLEs and problem behavior. Then four three-way repeated measure ANOVAs with internalizing and externalizing problem behaviors as dependent variables were performed. Time was added as within factor (problem behavior in early 
adolescence and adolescence), and SLEs were added as an independent variable in two analyses. Parental religiosity was added as an independent variable (once for internalizing and once for externalizing problem behavior), with correction for child's gender and SES. Planned pairwise comparisons (LSD) were performed in every analysis.

\subsubsection{Study population}

Descriptives of the dependent and independent variables are given in Table 1. In total, 2230 children (mean age $=11.09, S D=0.55$ ) were enrolled in the study (i.e. both child and parent agreed to participate). $90.8 \%$ of the parents reported to have a Christian religion. In early adolescence, 2149 children participated (mean age $=13.57, S D$ $=0.53)$ and in adolescence, $1881(84.3 \%$, mean age $=19.08, S D=0.60)$ still participated. Gender was equally distributed and about $20 \%$ of the pre-adolescents had divorced parents. The median SLE score was 0.52 (range $=0.00-13.00)$.

Table 1

Descriptives of the dependent and independent variables

\begin{tabular}{|c|c|c|c|}
\hline Independent variables & & $n$ & $(\%)$ \\
\hline Gender & Girls & 1132 & $50.8 \%$ \\
\hline \multirow[t]{2}{*}{ Divorce of parents } & Yes & 476 & $21.3 \%$ \\
\hline & $\operatorname{Max}$ & Mean & $\pm S D$ \\
\hline Total SLEs in 2 years before early adolescence & 13 & 0.52 & \pm 0.29 \\
\hline Religiosity variables & & $n$ & $(\%)$ \\
\hline \multirow[t]{6}{*}{ Parental religiosity } & Religious disharmony & 243 & $10.9 \%$ \\
\hline & Religious dysbalance & 77 & $3.5 \%$ \\
\hline & Non-religious harmony & 891 & $40.0 \%$ \\
\hline & Passive religious harmony & 345 & $15.5 \%$ \\
\hline & Active religious harmony & 398 & $17.8 \%$ \\
\hline & Missing & 276 & $12.4 \%$ \\
\hline Dependent variables & & Mean & $\pm S D$ \\
\hline \multirow[t]{2}{*}{$Y S R^{*}$ (early adolescence) } & Internalizing & 0.33 & \pm 0.24 \\
\hline & Externalizing & 0.29 & \pm 0.20 \\
\hline \multirow[t]{2}{*}{$A S R^{* *}$ (early adolescence) } & Internalizing & 0.25 & \pm 0.23 \\
\hline & Externalizing & 0.25 & \pm 0.21 \\
\hline
\end{tabular}

${ }^{*}:$ YSR $=$ Youth Self-Report ${ }^{* *}:$ ASR $=$ Adult Self Report 
Table 2

Prevalence of stressful life events in the two years before early adolescence

\begin{tabular}{|c|c|c|}
\hline & SLEs & Prevalence $(n, \%)$ \\
\hline 1 & Serious illness/accident & $364(17.4)$ \\
\hline 2 & Serious illness/accident of a family member & $515(24.7)$ \\
\hline 3 & Serious illness/accident of a close friend & $179(8.6)$ \\
\hline 4 & Death of mother & $14(0.7$ \\
\hline 5 & Death of father & $15(0.7)$ \\
\hline 6 & Death of brother or sister & $11(0.5)$ \\
\hline 7 & Death of someone else you cared about & $775(37.1)$ \\
\hline 8 & Death or loss of a pet & $757(36.2)$ \\
\hline 9 & Repeating a grade & $123(5.9)$ \\
\hline 10 & Dismissal from school & $31(1.5)$ \\
\hline 11 & Parental unemployment & $141(6.8)$ \\
\hline 12 & Contact with the police & $238(11.4)$ \\
\hline 13 & Loss of friendship due to conflict & $227(10.9)$ \\
\hline 14 & Romantic break up & $629(30.1)$ \\
\hline 15 & Parental divorce or separation & $117(5.6)$ \\
\hline 16 & Run away from home & $78(3.7)$ \\
\hline 17 & Loss of valuable stuff & $196(9.4)$ \\
\hline 18 & Victim of violence & $151(7.2)$ \\
\hline 19 & Almost victim of violence & $240(11.5)$ \\
\hline 20 & Victim of malicious rumor or gossip & $541(25.9)$ \\
\hline 21 & Victim of bullying & $524(25.1)$ \\
\hline 22 & Victim of sexual harassment & 249 (11.9) \\
\hline
\end{tabular}

\subsubsection{Data collection}

Well-trained interviewers visited one of the parents or guardians (mothers, 95.6\%), to ask them to fill out a questionnaire. Children filled out questionnaires at school under the supervision of one or more TRAILS assistants and were assessed individually. Teachers were asked to fill out a brief questionnaire for all participating TRAILS children in their class. 


\section{Results}

Parental religiosity was significantly associated with exposure to $\operatorname{SLEs}(\mathrm{F}(4,1949)=$ $2.440, p=0.045$, R squared 0.005) (Table 3). In pairwise comparisons, active religious harmony compared with parental non-religious harmony (mean item difference $0.05, p=0.004$ ) and parental religious dysbalance (mean item difference $0.074, p=$ 0.040 ) was associated with decreased overall SLE scores.

On an uncorrected regression analysis, SLEs were strongly associated with internalizing and externalizing problem behaviors $(\beta=0.453, \mathrm{t}(1639)=20.547, p<$ 0.001 and $\beta=0.408, \mathrm{t}(1652)=18.166, p<0.001)$, and this relationship was still present after correction for gender and SLEs $(\beta=0.420, \mathrm{t}(1639)=17.433, p<0.001$ and $\beta=0.385, \mathrm{t}(1652)=16.929, p<0.001)$. Repeated measures ANOVA analyses revealed no significant interaction effect between SLEs and parental religiosity in predicting either internalizing problem behavior $(\mathrm{F}(4,1440)=0.495, p=0.739, \eta 2=$ $0.001)$ or externalizing problem behavior $(\mathrm{F}(4,1437)=0.270, p=0.897, \eta 2=0.001)$ (Table 4).

\section{Table 3}

ANOVA, with stressful life events as dependent variable and parental religiosity as independent variables

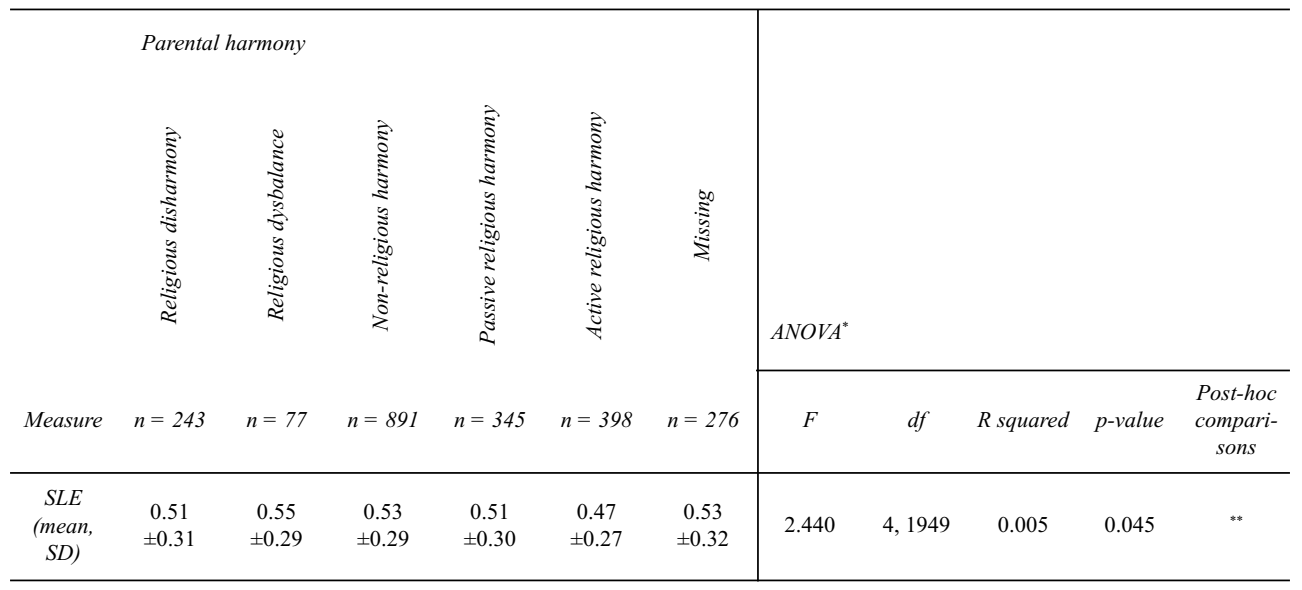

*: ANOVA performed without missing, ${ }^{* *}$ : description significant post-hoc comparisons under results 
Table 4

Repeated measures ANOVA for internalizing and externalizing scores for stressful life events with parental religiosity

\begin{tabular}{|c|c|c|c|c|c|}
\hline Measure & factors & $d f$ & $F$ & p-value & $\eta 2$ \\
\hline \multirow[t]{7}{*}{ Internalizing } & Stressful life events & 1,1435 & 3.089 & 0.079 & 0.002 \\
\hline & Time & 1,1435 & 15.751 & $<0.001$ & 0.011 \\
\hline & Stressful life events x Time & 1,1435 & 17.284 & $<0.001$ & 0.012 \\
\hline & Parental harmony & 4,1435 & 2.189 & 0.068 & 0.006 \\
\hline & Parental harmony $\mathrm{x}$ Time & 4,1435 & 0.624 & 0.645 & 0.002 \\
\hline & Stressful life events x Parental harmony & 4,1435 & 2.069 & 0.083 & 0.006 \\
\hline & Stressful life events $\mathrm{x}$ Time $\mathrm{x}$ Parental harmony & 4,1435 & 0.451 & 0.772 & 0.001 \\
\hline \multirow[t]{6}{*}{ Externalizing } & Stressful life events & 1,1432 & 2.306 & 0.129 & 0.002 \\
\hline & Time & 1,1432 & 85.959 & $<0.001$ & 0.057 \\
\hline & Stressful life events x Time & 1,1432 & 16.934 & $<0.001$ & 0.012 \\
\hline & Parental harmony $\mathrm{x}$ Time & 4,1432 & 0.805 & 0.522 & 0.002 \\
\hline & Stressful life events x Parental harmony & 4,1432 & 1.531 & 0.191 & 0.004 \\
\hline & Stressful life events $\mathrm{x}$ Time $\mathrm{x}$ Parental harmony & 4,1432 & 0.380 & 0.823 & 0.001 \\
\hline
\end{tabular}

\section{Discussion}

This study used data from the longitudinal TRAILS population cohort to learn more about the role of parental religiosity in protecting their children against the negative effects of SLEs on mental health. Parental religiosity may diminish exposure to SLEs or may diminish the negative effects of SLEs on problem behavior. We found that the more religious the parents were, the less their children were exposed to SLEs. However, we did not find parental religiosity to moderate the association between SLEs and problem behavior.

The association between parental religiosity and exposure to SLEs has been little studied to date. Our finding that having actively religious parents in pre-adolescence was associated with decreased exposure of their children to SLEs is probably the result of a combination of a value-oriented and protective upbringing (KOENIG et al. 2012). Moreover, not only is the home environment 'protective', but it is also likely that actively religious parents transmit their beliefs to their children (MYERS 
1996). Thus a child raised in a value-oriented environment is probably less likely to break traffic rules and hence less likely to be involved in a car accident. Such a child will probably have a less externalizing lifestyle, thereby decreasing the likelihood of exposure to certain types of SLEs.

We also hypothesized that religiosity would decrease the negative effects of SLEs on problem behavior. As reported in the literature (SERAFINI et al.2015; KING \& ROESER2009; BOUMA et al. 2008; BAKKER et al. 2010), we also found that SLEs were associated with increased problem behavior in both boys and girls. Some studies have reported religiosity to have a protective role against the negative effects of SLEs on internalizing (LAUFER et al. 2010; KABIRU et al. 2014) and externalizing problem behaviors (Johnson \& Morris 2008; Palamar et al. 2014; AmONe-P'OlaK et al. 2009). However, we did not find religiosity to have a protective effect. This might be because we assessed internalizing behavior as a sum score rather than as the score for individual internalizing behaviors, such as fear (LAUFER et al. 2010), or a measure of post-traumatic growth (KABIRU et al. 2014), which is certainly related to components of internalizing problems, but is a different concept as a whole. Likewise, we assessed externalizing behavior as a sum score, rather than as individual externalizing behaviors, such as delinquent behavior (JOHNSON \& MORRIS 2008; PALAMAR et al. 2014), substance and alcohol use (AMONE-P'OlAK et al. 2009).

Studies have measured religiosity in different ways, such as salience of religion and the extent of internalization of beliefs, whereas we used mostly behavioral measures, which are more distal ways of measuring salience of religion or internalization of beliefs. Also, two cognitive-behavioral models have been described as examples of the way religiosity may impact mental health via religious coping. However, appraisal of life events, and the several ways of self-regulation described, are more likely to be used if religion is very important to the individual (PARK 2005). In this study, a community-based longitudinal sample of pre-adolescents was used, with only $17.8 \%$ of the parents both being actively religious. This could explain why we did not find significant moderating effects in this study. Moreover, some earlier studies were performed in surroundings that are known for extreme SLEs (LAUFER et al. 2010; JOHNSON \& MORRIS 2008). Although our questionnaire on SLEs contained items on the death of an important person, other items concerned less serious SLEs, such as being bullied.

This study had several strengths and weaknesses. A particular strength is the longitudinal design of the TRAILS study, which enabled us to relate religiosity to SLEs and problem behavior in early adolescence and adolescence. A weakness of the study is that information about the religiosity of the father was provided by the mother. Further, $90.8 \%$ of the parents reported to have a Christion religion, which may hamper generalization towards other regions. Also, we did not assess participants for symptoms of trauma or PTSS. Further, many possible confounding factors were not taken into account. We hypothesized that having actively religious parents would be associated with less problem behavior, and that having actively religious parents would moderate the association between SLEs and problem behavior. 
Although we discussed findings in the light of religiosity, actively religious parents may have other characteristics that were - in this study - associated with exposure of their children to fewer SLEs, such as good parenting styles. Although we used socioeconomic status as a covariate in analyses, growing up in poverty could have distorted the results, as the influence of poverty is expected to outweigh the possible associations investigated in this article.

The practical implications of this study are as yet hypothetical, because the relationship between religiosity and SLEs was only weak, and because religiosity did not moderate the relationship between SLEs and problem behavior. However, it should be borne in mind that children, and people in general, can be exposed to SLEs at any time, and thus it is important to acquire knowledge about how to reduce the risk of SLEs and their negative effects on health and well-being.

In conclusion, although the present study cannot be compared to other studies in terms of study design and choice of measures for religiosity as well as internalizing and externalizing problem behaviors, the results are consistent with the modestly significant findings reported in other TRAILS studies (VAN DER JAGT-JELSMA et al. 2011; VAN DER JAGT-JELSMA et al. 2015; VAN DER JAGT-JELSMA et al. 2018; VAN DER JAGT-JELSMA et al. 2017). We found SLEs to be positively associated with internalizing and externalizing problem behaviors, and that having actively religious parents appeared to diminish the exposure of pre-adolescents to SLEs relative to that of pre-adolescents with non-religious parents (non-religious harmony) or parents that had different views about religiosity (religious dysbalance). However, religiosity did not moderate the association between SLEs and problem behavior as pre-adolescents matured into adolescents.

\section{References}

Achenbach, T.M. (1991) Manual for the Youth Self-Report and 1991 Profile (Burlington, VT: University of Burlington).

Achenbach, T.M. \& L.A. Rescorla (2003) Manual for the ASEBA Adult Forms \& Profiles (Burlington, VT: University of Burlington).

Amone-P'Olak, K., J. Ormel, M. Huisman, F.C. Verhulst, A.J. Oldehinkel \& H. Burger (2009) 'Life Stressors as Mediators of the Relation between Socioeconomic Position and Mental Health Problems in Early Adolescence: The TRAILS Study', Journal of the American Acadamy of Child and Adolescent Psychiatry 48, 1031-38 (http://doi.org/ 10.1097/CHI. 0b013e3181b39595).

BAKKer, M.P., J. ORmel, F.C. Verhulst \& A.J. Oldehinkel (2010) 'Peer Stressors and Gender Differences in Adolescents' Mental Health: The TRAILS Study', Journal of Adolescent Health 46, 444-50 (http://doi.org/10.1016/j.jadohealth.2009.10.002).

Bonelli R.M. \& H.G. KoenIG (2013) 'Mental Disorders, Religion and Spirituality 1990 to 2010: A Systematic Evidence-Based Review', Journal of Religion and Health 52, 657-73 (http://doi.org/ 10.1007/s10943-013-9691-4).

Bouma, E.M.C., J. Ormel, F.C. Verhulst \& A.J. Oldehinkel (2008) 'Stressful Life Events and Depressive Problems in Early Adolescent Boys and Girls: The Influence of Parental Depression, Temperament and Family Environment', Journal of Affective Disorders 105, 185-93 (http://doi.org/10.1016/j.jad.2007.05.007). 
Cotton S., K. Zebracki, S.L. Rosenthal, J. Tsevat \& D. Drotar (2006) 'Religion/Spirituality and Adolescent Health Outcomes: A Review', Journal of Adolescent Health 38, 472-80 (http://doi.org/10.1016/j.jadohealth.2005.10.005).

GeORGE L.K., C.G. ElLISON \& D.B. LARSON (2002) 'Explaining the Relationships between Religious Involvement and Health', Psychological Inquiry 13, 190-200 (http://dx.doi.org/ 10.1207/S15327965PLI1303_04).

Grant, K.E., B.E. Compas, A.F. Stuhlmachter, A.E. Thurm, S.D. McMahon \& J.A. Halpert (2003) 'Stressors and Child and Adolescent Psychopathology: Moving from Markers to Mechanisms of Risk', Psychological Bulletin 129, 447-66 (http://doi.org/10.1037/00332909.129.3.447).

HaCKNEY C.H. \& G.S. SAnders (2003) 'Religiosity and Mental Health: A Meta-Analysis of Recent Studies', Journal for the Scientific Study Religion 42, 43-55 (https://doi.org/10.1111/ 1468-5906.t01-1-00160).

JOHNSON C.J. \& R.G. MORRIS (2008) 'The Moderating Effects of Religiosity on the Relationship between Stressful Life Events and Delinquent Behavior', Journal of Criminal Justice 36, 486-93 (https://doi.org/10.1016/j.jcrimjus.2008.09.001).

Josephson, A.M. \& M.L.Dell (2004) 'Religion and Spirituality in Child and Adolescent Psychiatry: A New Frontier', Child and Adolescent Psychiatry Clinics of North America 13, 1-25 (https://doi.org/10.1016/S1056-4993(03)00099-3).

Kabiru, C.W., P. Elung' ATA, S.A. Mojola \& D. Beguy (2014) 'Adverse Life Events and Delinquent Behavior among Kenyan Adolescents: A Cross-Sectional Study on the Protective Role of Parental Monitoring, Religiosity, and Self-Esteem', Child and Adolescent Psychiatry and Mental Health 8, Nr. 24 (https://doi.org/10.1186/1753-2000-8-24).

KING, P.E. \& R.W. RoESER (2009) 'Religion and Spirituality in Adolescent Development' in R.M. LERnER \& L. STEInBerg Handbook of Adolescent Psychology: Volume 1: Individual Bases of Adolescent Development (Hoboken, New Jersey: Wiley) 435-78.

Koenig, H.G., M. McCullough \& D.B. Larson (2001) Handbook of Religion and Health (New York: Oxford UP).

Koenig, H.G., D. King \& V.B. CArson (2012) Handbook of Religion and Health (New York: Oxford UP).

Laceulle, O.M., R.J. Kleber \& E. Alisic. (2015) 'Children's Experience of Posttraumatic Growth: Distinguishing General from Domain-Specific Correlates', PLoS ONE 10(12) e0145736 (https://doi.org/10.1371/journal.pone.0145736).

LARSON, S.S. (1992) 'Associations between Dimensions of Religious Commitment and Mental Health Reported in the American Journal of Psychiatry and Archives of General Psychiatry: 1978-1989' American Journal of Psychiatry 149, 557-9 (https://doi.org/10.1176/ajp.149. 4.557).

Laufer A., Z. Solomon \& S.Z. Levine (2010) 'Elaboration on Posttraumatic Growth in Youth Exposed to Error: The Role of Religiosity and Political Ideology', Social Psychiatry and Psychiatric Epidemiology 45, 647-53 (https://doi.org/10.1007/s00127-009-0106-5).

Moreira-Almeida, A., F. Lotufo Neto \& H.G. Koenig (2006) 'Religiousness and Mental Health: A Review', The Revista Brasileira de Psiquiatria 28, 242-50.

MYERS, S.M. (1996) 'An Interactive Model of Religiosity Inheritance: The Importance of Family Context', American Sociological Review 61, 858-66.

Palamar, J.J., M.V. Kiang \& P.N. Halkitis (2014) 'Religiosity and Exposure to Users in Explaining Illicit Durg Use Among Emerging Adults', Journal of Religion and Health 53, 658-74 (https://doi.org/10.1007/s10943-012-9660-3). 
PARK, C.L. (2005) 'Religion as a Meaning-Making Framework in Coping with Life Stress' Journal of Social Issues 61, 707-29 (https://doi.org/10.1111/j.1540-4560.2005.00428.x).

Pargament, K.I. (1997) The Psychology of Religion and Coping: Theory, Research, Practice (New York: Guilford).

Pargament, K., M. Feuille \& D. Burdzy (2011) 'The Brief RCOPE: Current Psychometric Status of a Short Measure of Religious Coping', Religions 2, 51-76 (https://doi.org/10.3390/ rel2010051).

PiePer, J.Z.T. \& M.H.F. van Uden (2005) Religion and Coping in Mental Health (Amsterdam: Rodopi).

PiePer, J.Z.T., M.R. DE VRIES-Schot \& M.H.F. van Uden. (2012) 'Religious and Receptive Coping Importance for the Well-Being of Christian Outpatients and Parishioners', Archive for the Psychology of Religion 34, 173-89 (https://doi.org/10.1163/15736121-12341241).

Serafini, G., C. Muzio, G. Piccinini, E. Flouri, G. Ferrigno, M. Ompili, P. Girarde \& M. AMORE (2015) 'Life Adversities and Suicidal Behavior in Young Individuals: A Systematic Review', European Child and Adolescent Psychiatry 24, 1423-46 (https://doi.org/10.1007/ s00787-015-0760-y).

Van Der Jagt-Jelsma, W. (2018) Religiosity and Mental Health in Pre-Adolescents (PhD diss. University of Nijmegen, Linde).

Van der Jagt-Jelsma, W., M.R. de Vries-Schot, R. De Jong, C.A. Hartman, F.C. Verhulst, H. KLIP, P.A.M. van DEURzen \& J.K. BuitelaAR. (2015) 'Religiosity and Mental Health of PreAdolescents with Psychiatric Problems and their Parents: The TRAILS study', European Psychiatry 30, 845-51 (https://doi.org/10.1016/j.eurpsy.2015.07.006).

Van der Jagt-Jelsma, W., M.R. de Vries-Schot, R. DE Jong, F.C. Verhulst, J. Ormel, R. Veenstra, S. Swinkels \& J.K. BuitelaAr. (2011) 'The Relationship between Parental Religiosity and Mental Health of Pre-Adolescents in a Community Sample: The TRAILS study', European Child and Adolescent Psychiatry 20, 253-60 (https://doi.org/10.1007/ s00787-011-0171-7).

Van der Jagt-Jelsma, W., M.R. De Vries-Schot, P. Scheepers, P.A.M. van Deurzen \& J.K. ButtelaAr. (2017) 'Longitudinal Study of Religiosity and Mental Health of Adolescents with Psychiatric Problems: The TRAILS Study', European Psychiatry 45, 65-71 (https://doi.org/ 10.1016/j.eurpsy.2017.05.031).

Van der Jagt-Jelsma, W., M.R. De Vries-Schot, P.A.M. van Deurzen, H. Klip \& J.K. BuiteLAAR. (2018) 'Religious Harmony/Disharmony and Mental Health in Pre-Adolescents and Adolescents: The TRAILS study', Archives of Psychology 2:3 (March) 1-16, retrieved 12 Oct 2019 from https://archivesofpsychology.org/index.php/aop/article/view/42. 